\title{
THE DEVELOPMENT OF CREATIVITY IN CHILDREN STORY WRITING FOR INDUSTRY MORAL AND CULTURE BASED ON CREATIVITY NATION
}

\author{
Zulela MS \\ State University of Jakarta,Indonesia \\ Zulela@yahoo.com
}

\begin{abstract}
Abstrack
The development of this research aims to produce a set of models of teaching elementary school children to write stories that integrate approaches, methods, instructional media in developing creative writing children stories among elementary school students. In particular, this research is expected to produce outputs (products) in the form:1) a model in the development of primary school children to write stories, 2) examples Subjects who can lead the development of writing skills of primary school children's story, 2). Examples of children's story of the development of elementary school students, were excavated from the real experience of the students, the which can be built into a part of the creative industries are rooted in ideas of elementary school students. This research trying to empower the potential that exists in elementary school students. The second stage of the research that will come in the learning models will be implemented a to write stories (experimental) in elementary school, and the results will be applied in the form of models of teaching materials in writing stories and examples of stories. If this research can be continued into the third stage will be Followed by a revision of the results of children's stories written by elementary school students. Furthermore, mass production in cooperation with publishers and Obtain intellectual property rights
\end{abstract}

\section{Keywords: Writing, Children's Stories, Copyright}

Moral crisis has spread and infecting this nation. Bullying happens in schools, even now spreading to the primary school level. This can not be allowed to continue. Without the concrete steps this nation will continue to decline at the lowest point.

Moral dimension has a closely relation with dimensions of character. Every individual has a different moral judgment. This means, wherever or whenever people must have a honest character. Honest to God, honest to others and honest to himself. So, the moral crisis can be overcome with the development of character.

Within the scope of theschool,the entry point character development can be done in various ways, including through lessons with emphasis on the development of creative potential, especially in writing story. Norton (2008: 12) argues that fiction story can tell the story of life in children. In addition Sudaryanto asserted: Character coaching can be done through literature learning (story). That is, learning literary moral dimension. Story is the entry point to raise moral values; such as honesty, politeness, discipline, sacrifice, democracy.

In previous research that has been done in the years 2014, high-grade primary school students in particular have been able to create their ideas into various story. It would appear, if done with the right approach.

But in reality, the elementary school students who have the ability to tell a story, either orally or in writing, has not received attention, especially from teachers. But this potential has not fostered / explored optimally.

Moreover, the empirical data have found also in the elementary school, namely in elementary schools where undergraduate student while practical learning (PPL) in Jakarta area, they found that children's literature learning only given if the textbooks they use no poetry text, the text. For example, from the text on the book tells teacher to assigns the students according to instructions in the book, such as taking turns reading (without exercise correctly read poetry, interpreting), answered questions. The learning process is only done in the traditional way (customs) long, without 
anydevelopment idea. In the $2013^{\text {th }}$ curriculum, teachers can integrate the right literature learning (children's literature) in all subjects with any theme.

Especially in writing children's stories (children's literature) have a role in developing the talents / interests and character education through the characters in the story, which in turn expected to develop creativity, and also raise moral values- that based on Indonesia culture who came from the ancestors heritage of Indonesia from various regions.

\section{METHODS}

This study used Borg \& Gall research and development procedures. To implementing the learning model (test model) will experimentally. Furthermore Borg and Gall (1979) states that the method of research and development in principle, is a process to develop an educational product and subsequently validated.

Implementing models (trials) in the form of experimental models that will be carried out on small group comparing results to previous level story writing stories with the results after the implications of models arranged in this study.

If the purpose of this study (children's literature) produced in the implication of contextual models-constructivism) can not be achieved as expected, then the researchers will modify the method of research using methods / procedures, action research (action research) Kemmis Taggart namely with improvement implementation in the form of cycles.

Furthermore, in line with the opinion of the Borg and Gall on the other part (1979: 782), research and development is "a process used develop and validate educational product." Aiming to improve the quality of education. In addition to discovering new knowledge through 'basicresearch', or to address issues specific about the problems of a practical nature, with the aim to improve educational practices.

Research development of creativity in writing a story for students of high grade (grade V), Primary School was started from the phenomenon / potential seems when researchers attend Elementary Education students practical learning in Elementary School, specialized in teaching essay writing, and continued with research dissertation research in Primary Schools, Found a lot of students who have the potential to write, especially in the form of a story, either in the form of a story or a fictional or factual.

To modify the model of development research and action research. Stages of this research includes the following activities:(1)exploration qualitative, (2) implementating draft (test model) is the action (Action) and (3) the revision of the model and production development, in the form of product model of learning and children's stories.

Exploration activities are qualitatively used to explore the potential that there is a needs analysis with the assumption that the world, the reality of life and the events that occur as objects and phenomena of social, should be considered by way of an assortment of by people who are different, and to be understood through humanistic approach (Nasution: 1988: 12). Implementation of the design or test models of the development of creativity to write a story. Revision is a test of the effectiveness of the results / products in the form of models and results.

At this stage of pre development steps are as follows:

1. Collecting initial data that includes needs analysis, literature studies and field studies.

2. Planning for the development of research include formulating objectives, measures of research, design a learning model by examining the results of a needs analysis.

At this stage of the model development steps are as follows:

1. Development of the draft model of

2. Development of evaluation tools

Indicators measurable achievement in the first phase are as follows:

1. List of requirement analysis 
2. Details of the indicators model of learning to write children's stories SD integrating national culture in fifth grade elementary school,

3. The learning model development skills in elementary school children to write stories

The research instrument used see annex.

1. Interview Guide

2. Questionnaire, both the needs analysis developed by researchers. (Instrument / questionnaire) attached study.

This research using descriptive analysis with qualitative and quantitative strengthened. Outcomes in the first year is; (1) model of learning that develops the skills of elementary school children to write stories that can be used in particular elementary school teachers in implementing the learning process by integrating the morals and culture of Indonesia. In the second stage model revision is done through group discussions, which consists of;

1. Education expert Elementary School

2. Teachers / Principals Elementary

Furthermore measurable achievement indicators in the second year are as follows:

1. Revision / refinement of the learning model

2. Guide model development and teaching materials development capability to write children's stories as a creative industry that integrates the nation's culture.

Furthermore, achievement of measurable indicators in the third year are:

Book collection of children's stories and the publication of a public elementary school to obtain copyright.

\section{Research Year I: Pre-Development And Development Model (Product; Draft Model)}

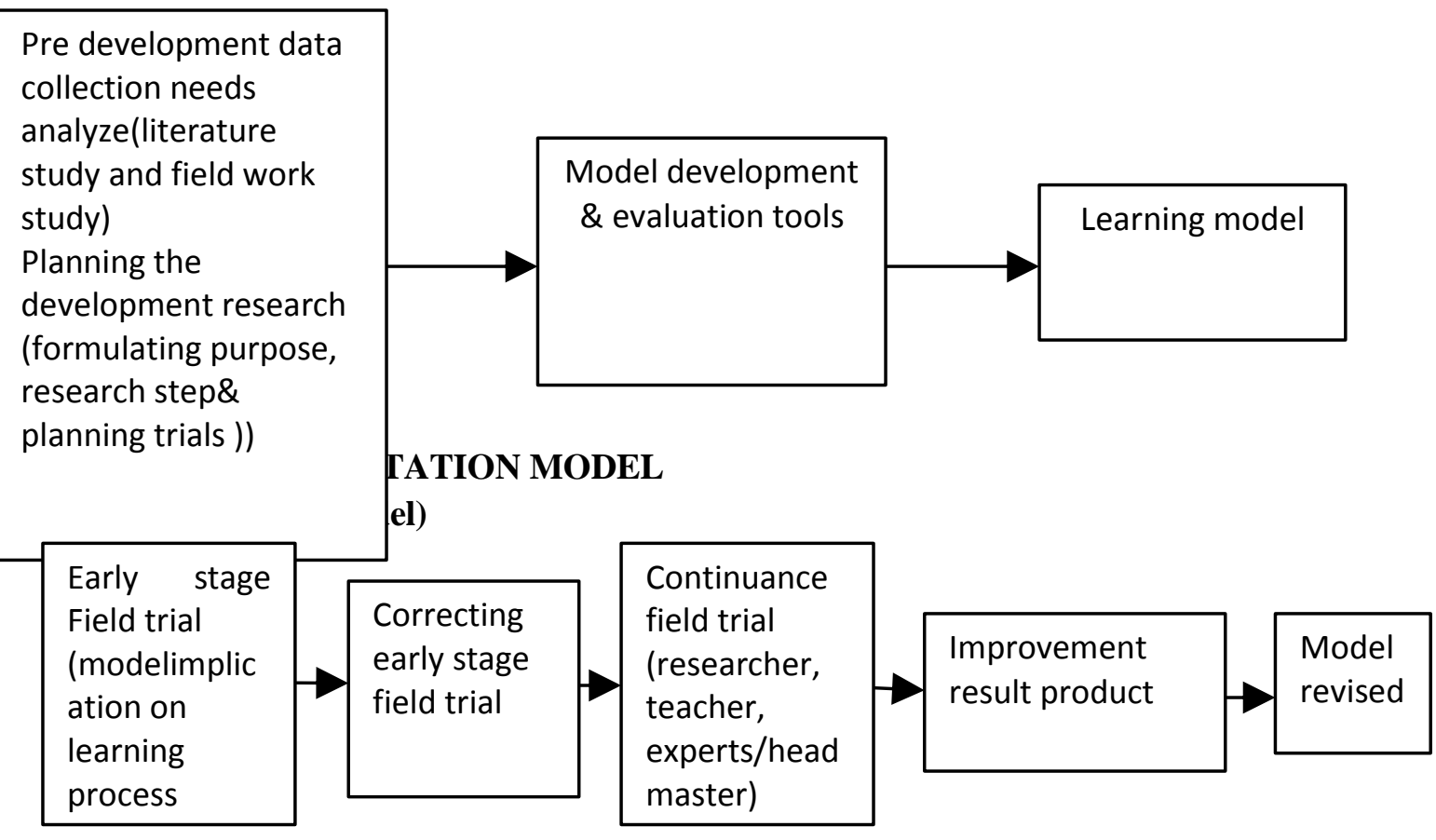

Figure .1 Method Research

Needs Analysis Writing Ability Development Model Primary School Children who Integrating Moral Values

Based on the needs analysis of the development model the ability in elementary school children to write stories based on cultural moral nation in Jakarta elementary school region South Jakarta which includes: SDN 01 Pondok Pinang, South Jakarta, SD land 03 KramatPela South 
Jakarta, SD NegeriKaretSetia Budi, South Jakarta and SD Laboratory PGSD FIP UNJ South Jakarta, which analyzes the results of interviews with teachers and principals in appendix 1 and 2.

Based on the results of questionnaires and interviews regarding the development model needs students' creativity in writing children's stories as the creative industries are based moral captured from the teacher and the Head master, shows that the need to develop creativity in elementary school children to write stories as a creative industry based moral; teachers and principals are very happy if development students creativity in writing stories that integrate this moral implemented well in primary school. It is caused by teachers and principals know that elementary school students either low grade (1,2 and 3) and high grade (4, 5 and 6) are mostly pleased with the story.

This is indicated by when teachers at a grade of 1,2 or 3 gives the lesson by telling a story, the students will be happy, sit closely following the story. The students give a pleasant reaction in accordance with the content of the story is played. Furthermore, typewriting given the test of authentic then $95 \%$ of students can answer. The ability of students will be increased if the story told through live images (movies)

Obstacles encountered; a teacher can not provide on a regular basis because of lack of teaching materials and real learning model that can be used as reference Elementary School. Therefore, they could not agree. if available / No model of learning and teaching materials as a reference for teachers in developing students' creativity in a productive writing in elementary school, which in turn can be nurtured in order to be developed into a creative industries starting from primary school.

Furthermore, there was information that the current elementary school teachers in general do not carry out the development of writing skills that lead to the development of creativity. It was due to the limited knowledge they possess. Implementation of learning to write now only be given in accordance with the textbook available. Unfortunately, the existing teaching material that presents no intact example in the development of writing skills, especially writing children's stories.

In the teaching of writing in high grade $(4,5$ and 6$)$ primary school teachers often find the students' good results, but never acted upon like a bada exchanged with friends, edited by a friend, or teacher. Activities undertaken limited on display on a bulletin board.

\section{Results Learning Development Model Development Elementary School Children's Writing}

People knowledge not a set of facts, concepts or rules that are ready to be retrieved or remembered, but man must construct and give meaning through real experience. In this case the student must be used to solve problems, find something useful. In a constructivist approach is more emphasis on the process of getting something rather than results.

Therefore, the task of the teacher is learning approach; facilitate learning process by means of, among others; (1) provide an opportunity for students to find and implement his own ideas, (2) sensitize the students to apply their learning strategies, and (3) make it meaningful to students' knowledge.

Furthermore Zahorik suggests there are five elements of learning constructivism, namely: (1) activation of existing knowledge (activating knowledge), (2) the acquisition of new knowledge (acquiring knowledge), (3) understanding of knowledge by means of drafting a while (hypotheses), do sharing with others, revise and develop, (4) practicing knowledge / experience it, (5) to reflect on the development strategy (Department of Education; 2003: 7) Furthermore, in another part zahorik explain that particular language learning in a constructivist approach is given by the approach communicative, the students are encouraged to use language appropriate to the real context.

Constructivist students are trained to solve problems, find something useful, and develop ideas. trained students construct knowledge in his mind, and transform complex information into another situation. On that basis it must be packed in the learning process of 'constructing' instead of 
receiving knowledge. Students become subject / activity center, while the teacher as facilitator. So in this case the teacher must direct that the students: (1) to make knowledge / topics meaningful and relevant to students, (2) provide an opportunity for students to find and implement his own ideas, (3) sensitize the students to apply the strategy according to their interests in learn.

Jonasson was quoted Smith (1991: 88) argues that the constructivist approach "learners construct something based on knowledge-knowledge / experience possessed for use as a perception of something or object and new events.

Gagnon and Collay (. $2001:$ : 7-10) suggested that the design of the learning system in a constructivist approach consists of several components, namely: 1) Situation, 2) Grouping, 3) Associates, 4) Question, 5) Ekssibisi, and 6) Reflection.

Situation, outline the components comprehensive about the intent / purpose of learning activities.Grouping, these components provide an opportunity for students to interact with peers. Grouping can be done at random or random.Attribution,this component is to connect the knowledge possessed by the students with new knowledge.Questions, component questions used to generate original ideas / original which is the core of a constructivist approach to build new knowledge.Exhibitions, this component provides the opportunity for students to demonstrate learning outcomes after following the learning process.Reflection, inipada components essentially provide an opportunity for students to think critically and apply knowledge of the learning experience that has been taken.

Based on the above reasoning, the researchers believe that the use of a constructivist approach in the development of creative writing story elementary school children will have a positive impact on the achievement of learning objectives, which in this occasion the aim to produce paper in the form of story-based elementary school children morals.

\section{Model Development of creativity in elementary school children to write stories as a creative industry can be described as follows :}

1

Eksploration:Students
has opportunitiy to find
their own ideas according
to the thme by reading,
observing

Students are invited towrite the concepts of a sequence of stories as they known. Teacher guide with a question..

Students arranged to revealed the reflecting result with guidance: maybe fun experience, funny, etc
2

Students reveal things
they had known that
related to the theme

Students are invited to observe the plot a course to an object and shown an short sentence for example

Students exchange reading in pairs and giving opinion each other with guidance (teacher, researcher, experts)
3

$$
\begin{aligned}
& \text { Students try to tell } \\
& \text { stories with a peer } \\
& \text { group }
\end{aligned}
$$

Students are invited to reflect to find the idea about the story that they wanted to reveal. On the other side they heard song instruments

Students develop writing and revise writing results freely (can be done in the library,park, classroom, etc)

Students develop their stories that their write by trying to beautify the look with colors, some pictures according to their creativity. And then displaying the work of students in rotation, read and choose the best stories with a reason. 


\section{Figure 5.1.Principles of Learning Approach Constructivism}

In designing the learning model of narrative writing using a constructivist approach to learning to write narrative, the researchers propose principles that are constructed as follows:

1. Students are guided and conditioned to always follow the learning process actively and always directed to able to construct ideas and then implement in accordance with the real communicative context of the various inputs, such as through the questions inducement.

2. Teachers guide students express a variety of problems encountered and communicating the appropriate experience, reflect and express language that can be understood.

3. Students are conditioned to explore in order to allow students construct meaning.

4. Students are given the opportunity to learn socially through interaction with peers, teachers and others in a learning situation that allows students to work together in a group discussion, ask each other and give each other feedback.

5. Teachers guide and facilitating students in order to optimize the knowledge that has been owned by the well / well. For this teacher always tries to appreciate the development of students according to the theory of learning, so teachers can assess and create conditions more accurate about what kind of learning relevant to students faced.

6. Learning activities are always adjusted to the previous preconditions, so that new conditions are not abstract for students, but there is always something to do with what is already known beforehand students. It is also in line with the opinions Glasersfelt (2001: 8), that in constructivism: Teaching is to empower students, and creates possibilities for students to find and reflect realistic experience, so that will make learning authentic / original and a deeper understanding of the course which is oriented on the surface memorization. So the point here in a constructive learning better use learning materials arehand-on of the textbook.

\section{DISCUSSION}

Learning to write a narrativecan be increased, if the teacher is able to carry out learning by using approaches, methods, strategies varied, in accordance with the tendency / characteristics of elementary school students. In addition, teachers must optimize the use of facilities / aids in accordance with approaches designed appropriately.

Learning to write with a constructivism approach combined with a contextual approach, is one of the appropriate approach to improve the ability to write essays (narrative) in high-grade primary school students.

With this approach the students are exposed to things challenging and is associated with everyday life in real time, or in other words, empowering anything that has been known to the students, such as what has been experienced. Students are given the opportunity to construct the knowledge that already exists in itself and is integrated with the new knowledge, which were carried out by using Indonesian well as the media.

Learning conditions must be created through a communication which is acceptable to students. Thanking here meant, by selecting the appropriate diction, intonation friendly and packed in learning situations that condition the students in a fun learning situation. Tools / learning strategies can be done by showing pictures of objects they have known, were invited to observe the story books as a model, and work in groups, so as to create communication amongst friends so provoke ideas and increase vocabulary.

Furthermore, essay writing activities with a fun activity, which is close to the world of children. This, among others, with diverse modeling to increase students' interest in writing. These conditions seem to encourage the curiosity of students to be skilled at creating works such as the models presented story, which begins with the student asked. 
In addition, students write more smoothly impression gained from experience, through a referral by the question of provocation. That way, students can more courage to express ideas / ideas to be disclosed.

From a series of models used by researchers apparently showing the typical significance of each model. Model pictures / photos, help remind the child will past experience, coupled with pencingan questions.

Model evoke vivid images more students to question things that are not yet understood, and help students to sequence the events in the story (chronologically), and use vocabulary skills are more developed.

While the contextual model, by inviting students to visit public places, such as traditional markets are very close to the children, so that children are freer to express feelings about the events seen / in his imagination by using words everyday.

If the ability to put the idea or ideas on students already appeared and vocabulary is a lot, then the technique of writing paragraphs and writing the correct letter, to explain again, given the real examples of its use as sticking examples of letters, punctuation at the wall. Thus, it is expected katerampilan students in writing a narrative can achieve optimal results.

However, behind the increase in the can, one side of which can not be improved is to improve students' writing. Diverse forms of writing students, some use block letters, writing letters upright mixed with printing, and a small portion mixed italic letters separated. The size of the students' writing was still not organized. There were two columns, one column and so on.

To overcome this, it seems that can not be fixed in one smester, but require continuous guidance by primary school teachers, ranging from writing beginning in the lower classes, and continued to write further by high grade teachers.

In addition, keep in mind, that the act of writing, not only in learning Indonesian, but integrated in all subjects or on any occasion to write in any lesson.

For more details, below presents a summary of the research results in the class action.

\section{CONCLUSION}

The process of research and development carried out has resulted in the learning model that develops creativity in elementary school children to write stories with moral integrate excavated from the culture of Indonesia.

The model that has been developed is expected to be a reference for elementary school teachers, especially in developing students' creativity in writing children's stories, which can eventually be developed into a creative industry.

\section{SUGGESTIONS}

Expected inidapat research results serve as a model / reference to the development of creativity in writing a children's story for elementary school teachers in the field, especially in the context of the integration of the dimensions of attitudes (religious and social attitudes) which is one of the focus / goals in the curriculum of 2013. It clearly can be regarded as one of the tools of character education learning process.

\section{REFERENCES}

Black, S. (2003).The Creative Classroom, American School Board Journal.

Borg R. Walter; Gall Meredith D. (1989).Educational Research; An Introduction,Fith Edition; Longman.

B.Rahmanto. (1988).Teaching Methods Literature.Yogyakarta: Doubleday. Education Ministry, Director General of Higher Education, (2005).Pembelajaran.2005 Quality Improvement.

Department of Education. (2003).Contextual Approach.Jakarta:Dikdasmen. 
DorotyEinon. (2002).translators; AlexandersChildren's Creative (Creative child). Batam, Karisma Publishing Group.

Gagnon, GW, and Collay. (2001).Designing for Learning: Six Elements in constructivist Clasrooms.Clifornia: Corwin Press, Inc.

HarisEfendiThahar. (2008). Creative Writing.Padang: UNP Press.

Dept. Industry. (2014). Indonesia Creative Industry Development in 2025.

Kemendikbud. (2013).Curriculum SD / MI in 2013

Mark.K.Smith, Theory of Learning and Teaching.Jogyakarta: Mirza Media Library.

Norton, Donna.E. (1988).ThrougThe Eyes Of A.Child: An Introduction To ChildrensLiteraure Columbus, Ohio: Ch. Merrill PulisingComp.

Robert E.Slavin. (2009).Education Psychology Theory and Practice, ed.8 Translation MariantoSamosir.Jakarta: PT Indekss.

Sugiyono, Prof.Dr. (2008).Educational Research Methods, Bandung: Alfabeta.

Sudaryanto. (2009).Teaching Literature Moral Dimension, Repuplika, February $2^{\text {nd }}$.

Sokolik in Caroline t. lines. (2008). Practical English Language Teaching YoungLearners,New York: Mc. Graw Hill.

Torrance, EP, A.There-stage Model for Teaching for Creative Thinggkingin AE Lawson (ed), The Yearbook AETS

------- (1998).Psychology of Teaching for Thingking and Creativity. Ohio: Clearinghouse.

YakobSumarjo. (1984).Understanding Kesusastran, Bandung:Alumni. 